\title{
The impact of an income-generating activities programme on children and mothers' undernutrition in extreme poor rural Bangladeshi households
}

\author{
Rie Goto ${ }^{1, *}(1)$, Joe Devine ${ }^{2}$, C.G. Nicholas Mascie-Taylor ${ }^{1}$, Justin Ormand ${ }^{3}$ \\ and Jufry Abdul Jabber ${ }^{4}$ \\ 'Department of Archaeology and Anthropology, University of Cambridge, Pembroke Street, Cambridge CB2 3QG, \\ UK: ${ }^{2}$ Department of Social and Policy Sciences, Centre for Development Studies, Bath University, Claverton Down, Bath \\ BA2 7AY, UK: 'International Development Unit, Ecorys, Queen Elizabeth House, St Dunstan's Hill, London EC3R 8AD, \\ UK: ${ }^{4}$ EEP/shiree, Mohakhali, Dhaka 1212, Bangladesh
}

Submitted 20 June 2018: Final revision received 14 April 2018: Accepted 3 May 2019; First published online 12 September 2019

\begin{abstract}
Objective: The current study assessed changes in children and mothers' nutritional status before and after raising Bangladeshi households out of extreme poverty through an income-generating activities (IGA) programme.

Design: Extreme poor households took part in the IGA programme for 2 years and recruitment took place over four waves in annual cycles. Children and mothers were measured with regarding their nutritional status before and after the IGA programme commenced.

Settings: Rural Bangladesh.

Subjects: Three-hundred and eighty-two children under 5 years of age at recruitment, and their mothers.

Results: After 2 years of the IGA programme, the prevalence of stunting significantly declined from $40.3 \%$ to $33.0 \%(P=0.003)$, anaemia declined from $51.6 \%$ to $44.0 \%$ $(P=0.020)$ while mothers' CED (Chronic Energy Deficiency) declined from $52.0 \%$ to $42.7 \%(P<0.001)$, but no significant changes were found in children's wasting, declining from $25.4 \%$ to $21.5 \%$, underweight which remained the same at $43.2 \%$, while mothers' anaemia rose from $39.3 \%$ to $42.7 \%$. There were also highly significant improvements in household socio-economic status. Increases in socioeconomic security (especially in relation to cash savings and net income) and improvements in food quantity and quality (indicated by greater food diversity and animal food intake) were associated with normal nutritional status, and cessation of open defecation was associated with reduction in mothers' and child anaemia. Conclusion: The IGA programme was associated with increased household socioeconomic security, such as asset accumulation, food security and sanitation, and with improvements in the nutritional status of children and their mothers in extreme poor households.
\end{abstract}

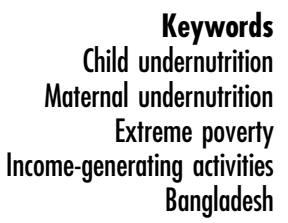

Child undernutrition is one of the world's most serious international development challenges. Undernutrition is caused by a combination of inadequate diet (both quality and quantity) as well as repeated infectious diseases ${ }^{(1)}$. Nearly half of all deaths of children under the age of five are attributable to undernutrition ${ }^{(2)}$. Poor nutritional status is usually determined by a lack of either weight or height for one's age (underweight and stunting, respectively), being thin for one's height (wasting), or deficiency in vitamins and minerals ('hidden hunger' such as anaemia). Those who survive childhood undernutrition are more likely to suffer from poorer cognitive functions ${ }^{(3)}$, a less resilient immune system $^{(4)}$ and, in later life, cardiovascular diseases and metabolic diseases such as diabetes ${ }^{(5)}$. Furthermore, females who suffer undernutrition are more likely to give birth to undernourished babies ${ }^{(6)}$, thereby continuing the intergenerational transmission of life-threatening disadvantage. Unlike many other forms of disadvantage however, the impacts of child undernutrition are difficult to reverse $^{(7,8)}$. The Sustainable Development Goals have 
committed to ending all forms of undernutrition by 2030 , including agreed targets on stunting and wasting in children. This is an ambitious target, riding on what appears to be an unprecedented and strong global momentum to address child undernutrition ${ }^{(9)}$. Given the prevalence and intractable nature of child undernutrition, the challenge lies in converting a global commitment into effective practice.

According to the 2016-2017 Global Competitiveness Report, South Asia has overtaken China as the world's fastest growing region, reflecting a track record of strong and stable economic growth and momentum as well as years of investment in health and education ${ }^{(10)}$. And yet, South Asia is also one of the regions in the world where child undernutrition is highest. Despite recent progress in reducing the prevalence of child undernutrition, South Asia is still home to $40 \%$ of the world's stunted children ${ }^{(2)}$. Unfortunately this is not a new observation. Some 20 years ago, Ramalingaswami and colleagues described the prevalence of undernutrition in the subcontinent as the 'South Asia

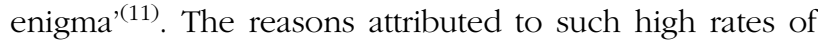
undernutrition in South Asia include gender inequality ${ }^{(12)}$, poor sanitation ${ }^{(13)}$, poor diets and low dietary diversity ${ }^{(9)}$ and ineffective nutritional programmes ${ }^{(14)}$. While the overall scenario in South Asia looks bleak, Bangladesh offers some glimmer of hope and optimism. In 1974, three years after the country's Independence, the prevalence of stunting was $71 \%{ }^{(15)}$. This has decreased significantly to $36 \%$, while the prevalence rates for underweight currently stand at $33 \%$ and wasting at $14 \%{ }^{(16)}$. Meanwhile, $33 \%$ of underfives have anaemia ${ }^{(17)}$.

Notwithstanding progress, Bangladesh presents a number of intriguing challenges. First, while reduction rates are impressive, the prevalence of child undernutrition remains high. One in three children under the age of five in Bangladesh is still affected by stunting, and although rural-urban differences are decreasing ${ }^{(14)}$, the prevalence of stunting in rural areas is still higher ${ }^{(18)}$. Bangladesh is unlikely to meet the World Health Assembly target of $40 \%$ reduction in stunting by $2025^{(17)}$, and the reduction in stunting has not matched progress in other areas of socio-economic life. Bangladesh has enjoyed over a decade of strong and stable economic growth and achieved higher levels of social development than other countries with similar per capita incomes ${ }^{(19)}$. Thus, the final report on Bangladesh's progress against the Millennium Development Goals notes remarkable achievements in inter alia reducing poverty, increasing food security, improving primary school enrolment and ensuring gender parity in primary and secondary level education, improving immunisation coverage, reducing the incidence of communicable diseases, and lowering the infant and under-five mortality rate as well as the maternal mortality ratio ${ }^{(20)}$. The high prevalence of undernutrition sits uncomfortably with success in other areas of social development, particularly improvements in immunisation cover, reductions in communicable diseases, and decreases in infant and maternal mortality. It is not clear why this misalignment has occurred. Indeed, some authors have recently argued that the aetiology of stunting in Bangladesh is not clear ${ }^{(17)}$, thus strengthening the calls for further research and analysis into the specific characteristics of undernutrition in Bangladesh.

This paper seeks to make a distinct contribution to the understanding of child undernutrition. While it is universally acknowledged that poverty is an underlying cause of undernutrition, recent analysis of socio-economic inequities and stunting has highlighted a need to understand more about the poorest quintile. Thus, Rabbani et al., drawing on their analysis of six rounds of the Bangladesh Demographic and Health Survey data (1996/ 97-2014), found that a child from the poorest quintile was twice more likely to fail to reach their growth potential compared with a child from the richest quintile ${ }^{(21)}$. Bangladesh's macroeconomic position is buoyant and the country is currently on track to achieve middle-income status by 2021 . However, as it does so, there is evidence of increasing levels of inequality and concerns over how this might impact upon growth progress in other socioeconomic areas ${ }^{(22)}$. If inequalities continue to rise - as is predicted in Bangladesh - the challenge of tackling child undernutrition among the very poorest will intensify.

The Economic Empowerment of the Poorest (EEP) programme, also known as shiree - the Bengali word for 'steps' and an acronym for 'Stimulating Household Improvements Resulting in Economic Empowerment' - worked with nationwide national and international Non-Government Organisations (NGO) to implement income generating activities (IGA) for extreme poor households. Examples of IGA included the provision of livestock, working capital or equipment to start or grow businesses ${ }^{(23)}$. The programme, which ended in 2016, successfully moved $1 \cdot 19$ million extreme poor people, covering the bottom 3-4\% of the poorest households in the country, out of extreme poverty ${ }^{(24)}$, helped $80 \%$ of households achieve the Millennium Development Goal on sanitation, and supported over 1.17 million people surpass a food security threshold.

This paper examines the impact of the IGA programme on changes in child and mothers' undernutrition in rural Bangladesh as well as the interrelationships between nutritional status and socio-economic indicators using a unique dataset focused on the extreme poor.

\section{Methods}

\section{Study setting, intervention and sample selection}

The shiree programme ran from 2008 to 2016 and funded twenty-nine national and international NGO to deliver projects aimed at reducing extreme poverty in Bangladesh. The programme worked mostly in rural areas of Bangladesh with the highest concentrations of extreme 
poor including the northwest of the country (affected by seasonal hunger), the southern coastal belt (highly vulnerable to severe climatic shocks including cyclones), and the Chittagong Hill Tracts (an ethnically diverse region), and the northeast region (prone to devastating floods every year during the monsoon). The programme also worked in some urban slums in Dhaka, the country's capital city.

\section{Overview of the intervention}

A range of IGA programmes were supported under each project, based on the partner NGO's specific project design, and in consultation with each recruited household. These included asset (e.g. livestock, rickshaws, seeds and trees) and technology transfers (training), strengthening market linkages, development of small businesses (seed capital and skills), access to khas land (government owned land), and improving access to rights and social entitlements.

\section{Sample selection}

Extreme poor households were recruited into the programme based on the overall value of their assets and income before any intervention (including IGA) took place. Thus, extreme poor households had an income of less than 1500 Taka per month (1USD was equivalent to 70 Taka in 2010 and 78 Taka in 2016), possessed total IGA assets worth less than 3000 Taka, had no more than two meals per day for four months a year, had no access to or membership of any financial network, and did not own any cultivatable land.

In 2010, 2011, 2012 and 2014 new households were recruited into the programme, and from these random samples were selected for the study (320, 128, 192 and 704 households respectively, see Fig. 1), and followed up annually in March/April each year. The selected households were carefully checked with other households in the programme for homogeneity across a number of variables, including family size, age, gender of household head, having child(ren) under 5 years of age or not. In the combined household data across all four years of recruitment (total 1344 households) there were 449 households in rural areas with children under 5 years of age at baseline. The first child in the household was selected for the analysis. Urban children were excluded from the analyses because only one urban area was studied (Dhaka) where a high migration rate was observed, and, moreover, the characteristics of urban and rural households were very different and the IGA activities in urban areas were limited to non-farming or animal rearing.

\section{Data analysis}

Variables of socio-economic status

Both cash and in-kind income were ascertained based on thirty different sources and total expenditure on everyday household items (following the Bangladesh official Household and Income and Expenditure Survey guidelines ${ }^{(25)}$ ), and health and food expenditure were also calculated. Net income was calculated as the difference between household total income and total expenditure and the extent of cash savings was also determined. Food coping strategies were used as a proxy for household food security based on the World Food Programme (WFP) and the Food and Agriculture Organization definitions ${ }^{(26,27)}$, i.e. households were defined as food insecure if they used one or more food coping strategies in the previous $7 \mathrm{~d}$ from a total of nine strategies (consuming smaller portions, consuming fewer than three meals per day, consuming food of lower than normal quality, consuming gathered food, consuming no food in $24 \mathrm{~h}$, borrowing money to secure food, buying food on credit, sending family member elsewhere to eat, and giving more food to earning household members). To determine dietary quality, an indicator of food diversity was used based on the Food and Nutrition Technical Assistance (FANTA) household indicator guide ${ }^{(28,29)}$ measured by thirteen items (rice, flour, pulse, potato, green leafy and other vegetables, fruit, milk, eggs, fresh/dried fish, poultry and meat) consumed in the previous $7 \mathrm{~d}$. This question also allowed for an examination of animal protein intake, measured by consumption of poultry, meat and fish in the previous $7 \mathrm{~d}$. Two key health and sanitation indicators were selected for analysis: child health, measured by the presence of fever or diarrhoea (which are generally easily identified by mothers) in the previous $7 \mathrm{~d}$, and whether households did or did not practice open defecation (households tend to build latrines as disposable income increases).

\section{Nutritional measurements}

Children below 5 years of age and their mothers had their height and weight measured. Child height-for-age (HAZ), weight-for-age (WAZ), weight-for-height (WHZ) and Body Mass Index z-score (BMIZ) were based on WHO 2006 standards $^{(30)}$. Undernutrition was defined by a z-score $<-2.00$ for HAZ (stunting), WAZ (underweight), and WHZ (wasting). For those over 5 years of age, WAZ was replaced by BMIZ (thinness). There is a very high correlation between WHZ and BMIZ $(r=+0 \cdot 97)$, thus WHZ or BMIZ $<-2$ is referred to as 'wasting' in this paper. Mothers were defined as being undernourished if their Body Mass Index (BMI) was below 18.5 (Chronic Energy Deficiency, CED $)^{(31)}$. Technical Error of Measurement was performed and accepted with $>95 \%$ intra- and inter-observer $\operatorname{accuracy}^{(32)}$.

A blood spot was collected by finger prick and the haemoglobin concentration was determined using a portable HemoCue (HemoCue Ltd., Ängelholm, Sweden). Children were anaemic if haemoglobin concentration was below $110 \mathrm{~g} / \mathrm{l}$ for children younger than 60 months of age and below $115 \mathrm{~g} / \mathrm{l}$ for children between 5 and 11 years of age ${ }^{(33)}$. Women's cut-off for anaemia was below $120 \mathrm{~g} / \mathrm{l}$ for non-pregnant women and below $110 \mathrm{~g} / \mathrm{l}$ for pregnant women. 


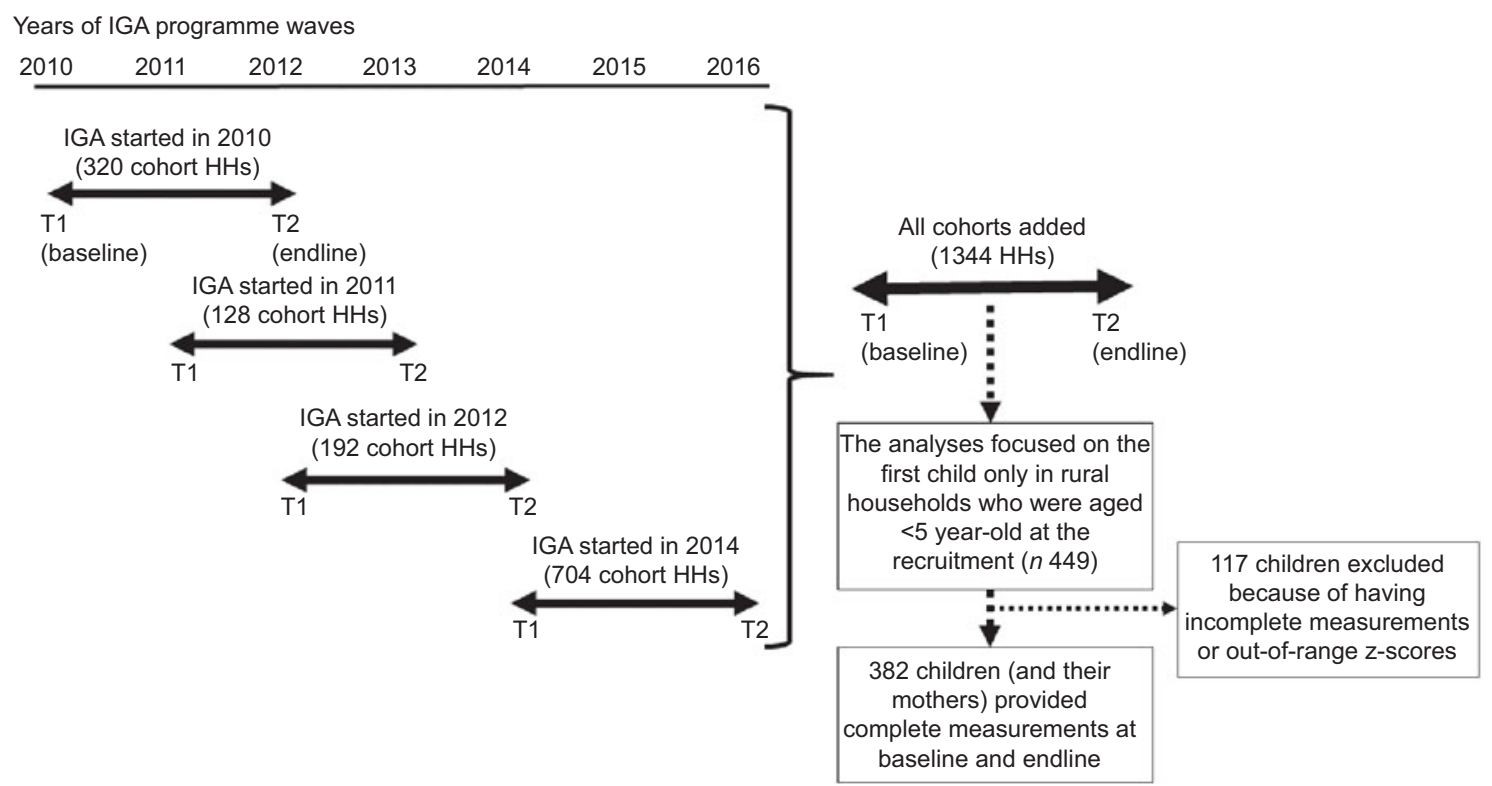

Fig. 1 The time and the cohort recruited in four waves of programme and the selection of the sample

\section{Statistical analyses}

Of the 449 children, 382 children provided complete measurements at baseline (T1) and endline (T2); 117 children were excluded because they were either absent on the day of the measurement $(N=96)$ or they had out-of-range Z-Scores using WHO criteria $(N=21)^{(30)}$. There were no significant differences between compliant (i.e. sample children) and non-compliant (the 117 children excluded) groups at baseline in terms of sex ratio, mean age and the four Z-scores. The prevalence of CED and anaemia in mothers was also not different. Although the locations and recruitment year varied in the four cohorts, there were no significant cohort differences of the four z-scores in children and prevalence of CED and anaemia in mothers at baseline, which allowed for an analysis of the four cohorts together.

Each type of nutritional status (stunting, underweight, wasting and anaemia in children and CED and anaemia in mothers) was analysed separately. Changes in the nutritional status of children and mothers were categorised as binary variables; (i) non-undernourished: in children, without stunting, underweight, wasting and anaemia at both baseline and endline (coded as 0), in mothers without CED and anaemia at both baseline and endline (coded as 0); and (ii) undernourished: in children suffering stunting, underweight, wasting and anaemia at baseline and/or at endline (coded 1), in mothers' CED and anaemia in mothers at baseline and/or endline (coded as 1).

Changes in continuous variables (net income, cash savings (logged), food and health expenditures (logged), food diversity (number of food items eaten in the last $7 \mathrm{~d}$ ) and food coping (number of strategies used in the last $7 \mathrm{~d}$ ) of households, animal protein intake (number of day eaten poultry, meat and fish in the last $7 \mathrm{~d}$ ) were calculated by subtracting endline value minus baseline value. The changes in the prevalence of fever or diarrhoea in last7 $\mathrm{d}$ was coded as a binary variable: (i) no fever or diarrhoea at both baseline and endline (coded as 0 ); and (ii) presence of fever or diarrhoea at baseline and/or endline (coded as 1). Similarly, change in open defecation was coded (i) not practising open defecation at both baseline and endline (coded as 1); and (ii) practising open defecation at baseline and/or endline (coded as 1). Paired-sample t-tests and McNemar tests were used to examine within-individual changes in nutritional status and socio-economic indicators (see Table 1).

After controlling for age and sex, a sequential binary logistic regression was used to test which socio-economic indicators best predicted changes in nutritional status (i.e. non-undernourished and undernourished); (i) testing each socio-economic indicator (net income, cash savings, food expenditure, health expenditure, food diversity and food coping strategies of household, animal protein intake, child health (no fever and no diarrhoea in the last $7 \mathrm{~d}$ or not) and sanitation (not practising open defecation of households or not)) separately; and (ii) those socio-economic indicators which showed significant associations with changes in nutritional status were used to create the best model (see Tables 2 and 3). All analyses were performed using IBM SPSS Statistics version 25.

\section{Results}

\section{Changes of children's nutritional status and socio-economic indicators over the 2 years}

At baseline, $40 \%$ of the children were stunted, $43 \%$, were underweight, about $25 \%$ were wasted, and more than a half of the children were suffering from anaemia (Table 1). 
Table 1 Child nutritional status and socio-economic indicators at baseline (T1) and endline (T2) and the changes over two years (T1-T2)

\begin{tabular}{|c|c|c|c|c|c|c|}
\hline & \multicolumn{2}{|r|}{ T1 } & \multicolumn{2}{|r|}{$\mathrm{T} 2$} & \multicolumn{2}{|c|}{$\mathrm{T} 1-\mathrm{T} 2$} \\
\hline & $N$ & $\%$ & $\mathrm{~N}$ & $\%$ & $\%$ Change & $P$ \\
\hline \multicolumn{7}{|l|}{ Child nutritional status } \\
\hline Stunting & 154 & $40 \cdot 3$ & 126 & 33.0 & $-7 \cdot 3$ & 0.003 \\
\hline Underweight & 165 & $43 \cdot 2$ & 165 & $43 \cdot 2$ & 0 & NS \\
\hline Wasting & 97 & 25.4 & 82 & 21.5 & -3.9 & NS \\
\hline Anaemia & 197 & 51.6 & 168 & 44.0 & $-7 \cdot 6$ & 0.020 \\
\hline \multicolumn{7}{|l|}{ Mother's nutritional status } \\
\hline Chronic Energy Deficiency (CED) & 191 & $52 \cdot 0$ & 158 & $42 \cdot 7$ & $-9 \cdot 3$ & $<0.001$ \\
\hline Anaemia & 150 & $39 \cdot 3$ & 163 & $42 \cdot 7$ & +3.4 & NS \\
\hline & Mean & $95 \% \mathrm{Cl}$ & Mean & $95 \% \mathrm{Cl}$ & Mean change & $P$ \\
\hline \multicolumn{7}{|l|}{ Socio-economic indicators } \\
\hline Net income (Tk) & 118.5 & $-2414.4,2584.5$ & 4710.9 & $-4668 \cdot 7,19262 \cdot 4$ & +4599.5 & $<0.001$ \\
\hline Cash savings* (Tk) & 3.9 & $0,1742 \cdot 6$ & $3508 \cdot 3$ & $0,44035 \cdot 2$ & $+4436 \cdot 1$ & $<0.001$ \\
\hline Food expenditure (Tk) & $1892 \cdot 9$ & $484 \cdot 4,4351 \cdot 1$ & $2944 \cdot 8$ & $825 \cdot 8,6636 \cdot 6$ & $+1038 \cdot 1$ & $<0.001$ \\
\hline Health expenditure* $(T k)$ & $20 \cdot 1$ & $0,800 \cdot 9$ & 29.1 & $0,3001 \cdot 2$ & +9.0 & 0.044 \\
\hline $\begin{array}{l}\text { Food diversity of household } \\
\text { (number of food items having last } 7 \mathrm{~d} \text { ) }\end{array}$ & $5 \cdot 86$ & $3.00,9.00$ & $9 \cdot 61$ & $5.00,13.00$ & $+3 \cdot 75$ & $<0.001$ \\
\hline $\begin{array}{l}\text { Food coping strategies of household } \\
\text { (number of strategy having last } 7 \mathrm{~d} \text { ) }\end{array}$ & $3 \cdot 13$ & $0,7 \cdot 00$ & 0.32 & $0,1.00$ & -3.07 & $<0.001$ \\
\hline $\begin{array}{l}\text { Animal protein intake (number of day } \\
\text { having poultry, meat and fish in the last } 7 \mathrm{~d} \text { ) }\end{array}$ & $0 \cdot 13$ & $0,1.00$ & $1 \cdot 24$ & $0,4 \cdot 00$ & $+1 \cdot 11$ & $<0.001$ \\
\hline $\begin{array}{l}\text { Child health (no fever and no diarrhoea } \\
\text { in the last } 7 \mathrm{~d} \text { ) }\end{array}$ & 294 & $77 \cdot 0$ & 345 & $90 \cdot 3$ & $+13 \cdot 3$ & $<0.001$ \\
\hline $\begin{array}{l}\text { Not practicing open defecation } \\
\text { of households }\end{array}$ & 207 & $54 \cdot 2$ & 341 & 89.3 & $+35 \cdot 1$ & $<0.001$ \\
\hline
\end{tabular}

Tk (1 USD = 70 Taka in 2010 and 78 Taka in 2016).

*Geometric mean was used.

After 2 years of the IGA programme, there were some significant improvements: the prevalence of stunting declined to $33.0 \%(P=0.003)$, and the prevalence of anaemia also declined to $44.0 \%(P=0.020)$. However, the prevalence of underweight did not change (remaining at $43.2 \%$ ) and the prevalence of wasted children reduced to $21.5 \%$ but it was not a significant reduction. In terms of mothers' nutritional status, 52\% suffered from CED and 39\% had anaemia at baseline. At endline, the prevalence of CED reduced significantly to $42.7 \%(P<0.001)$, and although anaemia slightly increased to $42.7 \%$, but this was not a significant change.

The EEP programme focused on reducing extreme poverty through IGA initiatives and, not surprisingly, there were highly significant improvements in household socio-economic status. Before the IGA programme commenced, extreme households had a net income of 113.5 Taka per month and little cash savings (3.9 Taka per household) with just under 2000 Taka to spend on food and about 20 Taka for health. Following the IGA, household net income increased nearly forty times, debt fell from $41 \%$ at baseline to $12 \%$ at endline (not shown in the table), cash savings increased 900 fold while food and health expenditure increased about 1.5 fold. Furthermore following the IGA, almost all households no longer relied on food coping strategies, dietary diversity increased from 5.9 items to 9.6 items, and households eating animal protein increased from $0.13 \mathrm{~d}$ to $1.24 \mathrm{~d}$ in the previous $7 \mathrm{~d}$. In terms of health and sanitation, at endline $90 \%$ of children had not suffered from either fever or diarrhoea in the previous $7 \mathrm{~d}$ and only $11 \%$ of households were using open defecation.

\section{Relationships between the changes in nutritional status of children and the changes in socio- economic indicators}

The changes from baseline to endline in cash savings, food expenditure, food diversity and mothers with CED were all significantly related to changes in stunting (Table 2). Households with non-stunted children (at both baseline and endline) had about $45 \%$ more cash savings (+3025 Taka), about $40 \%$ more food expenditure $(+336$ Taka) and 0.7 more items of food diversity than households where the child was stunted at baseline or endline $(P=0.006,0.036$ and 0.010, respectively). Households with stunted children were 1.6 times more likely to have mothers who did not change their CED at baseline or endline $(P=0.042)$. The model with the four significant variables predicted $59.7 \%$ of children not stunted and $53.2 \%$ of children suffering from stunting at either or baseline or endline (overall prediction was $56.5 \%$ ).

Changes in children underweight were significantly associated with changes in net income, cash savings, food diversity and animal protein intake as well as with having a mother with CED (Table 2). Households with nonunderweight children had about $58 \%$ more net income (+2110 Taka), $41 \%$ more cash savings (+2883 Taka), on average 0.7 more items of food diversity and $0.3 \mathrm{~d}$ more 
Table 2 Associations of the changes in socio-economic indicators and mothers' nutritional status with the changes in child undernutrition (only significant independent variables are shown)

\begin{tabular}{|c|c|c|c|c|c|c|}
\hline \multirow[b]{2}{*}{$\begin{array}{l}\text { Socio-economic indicators } \\
\text { (significant variables only) }\end{array}$} & \multicolumn{2}{|c|}{ Non-undernourished ${ }^{\star}$} & \multicolumn{2}{|c|}{ Undernourished* } & \multirow[b]{3}{*}{$P$} & \multirow[b]{3}{*}{ Best model } \\
\hline & $\begin{array}{l}\text { Estimated mean } \\
\quad \text { or OR }\end{array}$ & & $\begin{array}{l}\text { Estimated mean } \\
\quad \text { or OR }\end{array}$ & & & \\
\hline Stunting & $N 174$ & SE or $95 \% \mathrm{Cl}$ & $N 164$ & SE or $95 \% \mathrm{Cl}$ & & \\
\hline $\begin{array}{l}\text { Cash savings (Tk) } \dagger \\
\text { Food expenditure (Tk) } \\
\text { Food diversity (number of items) } \\
\text { Mother with CED } \ddagger\end{array}$ & $\begin{array}{c}9808 \cdot 4 \\
1192 \cdot 2 \\
4 \cdot 1 \\
1\end{array}$ & $\begin{array}{r}756.6 \\
109.0 \\
0.2\end{array}$ & $\begin{array}{c}6782 \cdot 6 \\
856 \cdot 0 \\
3.4 \\
1.561\end{array}$ & $\begin{array}{l}793 \cdot 2 \\
113 \cdot 9 \\
0.2 \\
1.014,2 \cdot 403\end{array}$ & $\begin{array}{l}0.006 \\
0.036 \\
0.010 \\
0.042\end{array}$ & $\begin{array}{l}P=0.001 \\
\text { Predicted }(\%) \\
\text { Normal } 69.5 \\
\text { Others } 49.4 \\
\text { Total } 59.8\end{array}$ \\
\hline Underweight & $N 156$ & & $N 182$ & & & \\
\hline $\begin{array}{l}\text { Net income }(T k) \\
\text { Cash savings (Tk) } \dagger \\
\text { Food diversity (number of items) } \\
\text { Animal protein intake (number of days) } \\
\text { Mother with CED } \neq\end{array}$ & $\begin{array}{r}5736 \cdot 9 \\
9914 \cdot 5 \\
4 \cdot 1 \\
1 \cdot 3 \\
1\end{array}$ & $\begin{array}{r}674.7 \\
806.6 \\
0.2 \\
0.1\end{array}$ & $\begin{array}{l}3626 \cdot 7 \\
7031 \cdot 2 \\
3 \cdot 4 \\
1 \cdot 0 \\
2 \cdot 140\end{array}$ & $\begin{array}{l}628 \cdot 2 \\
749 \cdot 2 \\
0 \cdot 2 \\
0 \cdot 1 \\
1.384,3.309\end{array}$ & $\begin{array}{l}0.023 \\
0.009 \\
0.003 \\
0.045 \\
0.001\end{array}$ & $\begin{array}{l}P=0.001 \\
\text { Predicted }(\%) \\
\text { Normal } 50 \cdot 6 \\
\text { Others } 72.0 \\
\text { Total } 62.1\end{array}$ \\
\hline Wasting & $N 240$ & & $N 115$ & & & \\
\hline Mother with CED $\ddagger$ & 1 & & 1.895 & $1 \cdot 177,3.050$ & 0.007 & $\begin{array}{l}P=0.007 \\
\text { Predicted }(\%) \\
\text { Normal } 100.0 \\
\text { Others } 0 \\
\text { Total } 67.6\end{array}$ \\
\hline Anaemia & $N 123$ & & $N 247$ & & & \\
\hline $\begin{array}{l}\text { Open defecation } \ddagger \\
\text { Mother with anaemiał }\end{array}$ & $\begin{array}{l}1 \\
1\end{array}$ & & $\begin{array}{l}1 \cdot 626 \\
2 \cdot 742\end{array}$ & $\begin{array}{l}1.050,2.519 \\
1.733,4.337\end{array}$ & $\begin{array}{r}0.028 \\
<0.001\end{array}$ & $\begin{array}{l}P<0.001 \\
\text { Predicted }(\%) \\
\text { Normal } 29.3 \\
\text { Others } 90.3 \\
\text { Total } 70.7\end{array}$ \\
\hline
\end{tabular}

*Changes in the nutritional status of children were categorised as binary variables: (i) 'non-undernourished' (coded as 0 ) included normal at both baseline and endline and (ii) 'undernourished' (coded as 1) included undernourished (i.e. stunting, underweight, wasting and anaemia) at baseline or/and endline.

†Cash saving was log-transfer and calculated estimated geometric mean after controlling for age and sex effects on children's undernutrition in the best model.

†Reference values in socio-economic indicators: Mother with CED; being not CED (0) and others being or became CED at baseline or/and endline as CED (1), Open defecation; not practising open defecation (0) and others practising open defecation at baseline or/and endline (1), Mother with anaemia; being not anaemic (0) and others being or became anaemic baseline or/and endline as anaemic (1).

eating animal protein in the last $7 \mathrm{~d}$ than those households with children who suffered from underweight at baseline and/or endline $(P=0.023,0.009,0.003$ and 0.045, respectively). Underweight children were $2 \cdot 1$ times more likely to have mothers who did not change CED $(P=0.001)$. The model with all five significant variables predicted $48.5 \%$ of non-underweight children and $72.8 \%$ of children suffering from underweight at baseline and/or endline (overall prediction was $61.6 \%$ ).

Changes in wasting of children were not associated with any of the socio-economic changes but were associated with mothers suffering from CED. Households with children who were wasted were 1.9 times more likely to have mothers who did not change CED $(P=0.007$, the overall prediction was $67.6 \%$, although the model predicted $100.0 \%$ of children not wasted and $0 \%$ of children with wasting at baseline and/or endline).

Changes in the prevalence of anaemia in children were associated with sanitation (practising open defecation) and the change in mothers' anaemia. Households with children who were anaemic were 1.6 times more likely to live in households practising open defecation. Children who were anaemic were 2.7 times more likely to have mothers who suffered from anaemia at baseline and/or endline $(P<0.001)$. The two variables predicted $29.3 \%$ of children with normal condition and $90.3 \%$ of children suffering from anaemia at either or both baseline and endline (overall prediction was $70 \cdot 7 \%$ ).

\section{Associations between mothers' undernutrition and socio-economic indicators}

Table 3 shows that households with non-CED mothers had $42 \%$ more cash savings ( +2100 Taka) than those households with mothers who had CED $(P<0.001)$. Mothers with anaemia were $2 \cdot 0$ times more likely to live in households practising open defecation at baseline and/or endline $(P<0.001)$. The changes of cash savings predicted $18.4 \%$ of non-CED mothers and $94.7 \%$ in mothers with CED (overall 63.1\%). Practising open defecation is a 
Extreme poor programme and child nutrition

Table 3 Significant associations between changes in socio-economic indicators and mothers nutritional status

\begin{tabular}{|c|c|c|c|c|c|c|}
\hline \multirow{2}{*}{$\begin{array}{l}\text { Socio-economic indicators } \\
\text { (significant variables only) }\end{array}$} & \multicolumn{2}{|c|}{ Not-undernourished ${ }^{*}$} & \multicolumn{2}{|c|}{ Undernourished* } & \multirow[b]{3}{*}{$P$} & \multirow[b]{3}{*}{ Best model } \\
\hline & \multicolumn{2}{|c|}{$N 147$} & \multicolumn{2}{|c|}{$N 208$} & & \\
\hline Mother with CED & $\begin{array}{l}\text { Estimated } \\
\text { mean or OR }\end{array}$ & $95 \% \mathrm{Cl}$ & $\begin{array}{l}\text { Estimated } \\
\text { mean or OR }\end{array}$ & $95 \% \mathrm{Cl}$ & & \\
\hline \multirow[t]{3}{*}{ Cash savings $(\mathrm{Tk}) \dagger$} & $7100 \cdot 0$ & $8842 \cdot 8,13087 \cdot 4$ & $5000 \cdot 0$ & $5531 \cdot 6,7993 \cdot 8$ & $<0.001$ & $\begin{array}{l}P<0.001 \\
\text { Normal } 18.4 \\
\text { Others } 94.7 \\
\text { Total } 63.1\end{array}$ \\
\hline & \multicolumn{2}{|c|}{$N 152$} & \multicolumn{2}{|c|}{$N 220$} & & \\
\hline & $\begin{array}{l}\text { Estimated } \\
\text { mean or OR }\end{array}$ & $95 \% \mathrm{Cl}$ & $\begin{array}{l}\text { Estimated } \\
\text { mean or OR }\end{array}$ & $95 \% \mathrm{Cl}$ & & \\
\hline Open defecation & 1 & & 1.981 & $1.300,3.019$ & $<0.001$ & $\begin{array}{l}P<0.001 \\
\text { Predicted (\%); } \\
\text { Normal } 100.0 \\
\text { Others } 0 \\
\text { Total } 59.1\end{array}$ \\
\hline
\end{tabular}

${ }^{*}$ Changes in the nutritional status of mothers were categorised as binary variables: (i) 'non-undernourished' (coded as 0 ) included normal at both baseline and endline and (ii) 'undernourished'(coded as 1) included undernourished (i.e. CED and anaemia) at baseline or/and endline.

†Cash saving was log-transformed and calculated estimated mean.

ҒOpen defecation: not practising open defecation is reference (0) and others at baseline or/and endline practising open defecation (1).

significant, but a poor, predictor (100\% of mothers not suffering from anaemia compared with $0 \%$ in mothers with anaemia (overall 59.1\%)).

\section{Discussion}

The most significant finding from this study is the reduction in chronic undernutrition and anaemia of children living in the very poorest households of Bangladesh. After two years participation in an IGA programme, stunting fell from $40.3 \%$ to $33.0 \%$ while anaemia fell from $51.6 \%$ to $44.0 \%$. The prevalence of stunting fell from above to below the national average (36\%) while anaemia remained above the national figure (33\%) for under-five year olds ${ }^{(19)}$. The national annual average rate of stunting reduction is $2.8 \%$ over the period of $1996-2011^{(34)}$ which is less than that observed in this study, reinforcing the notion the poverty is the underlying cause of undernutrition ${ }^{(1)}$. From these analyses, it can be concluded that it is possible to bring about a substantial improvement in the nutritional status of children in extreme poor households by addressing the core socio-economic needs of the same households. Nutrition specific interventions bring obvious benefits ${ }^{(35-37)}$ but the current analyses suggest that tackling household socioeconomic vulnerability is an effective way to reduce undernutrition. Furthermore, given the growing inequality in Bangladesh, the prospects of further reducing child undernutrition will depend on the effectiveness of programmes that address the socio-economic disadvantages experienced by the extreme poor. In policy terms, this suggests that targeting extreme poor households and other marginalised groups may be a more preferable option that extending universal coverage.

Households without stunted or underweight children had 41-45\% more cash savings, and households without underweight children had 58\% more net income. Wealth or income are one of the strongest predictors of poor nutritional status ${ }^{(9)}$, and this is true for Bangladesh ${ }^{(21)}$. Cash savings is a proxy of wealth accumulation and provides a safety net to ease problems of households who fall into a 'shock' resulting from, for example, ill health or loss of employment ${ }^{(38)}$. The IGA programme provided households with long-term economic security and stability, which is associated with a significant reduction in stunting ${ }^{(1)}$.

This study, however, did not find any significant change in the prevalence of children's weight growth, i.e. underweight and wasting, before and after the IGA programme. As shown by Ngwira et al. (2017) the pathways by which children become stunted, underweight and wasted are complex and different; stunting is primarily a failure of linear growth while underweight and wasting are related to lack of muscle and fat mass ${ }^{(39)}$. South Asian children may not develop much lean body mass during infancy due to mother's low BMI and the condition also remains at older ages, which may explain the persistence of wasting ${ }^{(40)}$. The improvement in the quality of food observed in this study, however, may not be sufficient to reduce underweight and wasting significantly. For example, de Groot et al. (2016) reviewed the impact of cash transfer programmes in Latin America and sub-Saharan Africa on child nutrition based on six systematic reviews and meta-analysis, and did not find any conclusive evidence of a positive impact 
of the programmes on child nutritional status. They concluded that the mechanisms of impact on child nutrition were not clearly understood ${ }^{(41)}$.

Food security and dietary quality are prime determinants of a child's nutritional status ${ }^{(1)}$, and this finding has been repeatedly observed in Bangladesh ${ }^{(18)}$. People become food insecure not because of food unavailability but because they cannot afford it or cannot access it. For example, as a direct result of the 2011 global hike in food prices, almost $70 \%$ of all households in Bangladesh experienced some form of food insecurity. However, the impact on the extreme poor was significantly greater as they ended up spending a far larger percentage of their income on food ${ }^{(42)}$.

Children with any form of undernutrition were 1.6-2.1 times more likely to have mothers with CED or anaemia. Maternal iron status during pregnancy reflects infant's iron endowments ${ }^{(43)}$. Foetal iron stores increase as the foetal liver grows, and most ( $>66 \%$ ) of the infant's total body iron is acquired during the final trimester. An infant weighing $1500 \mathrm{~g}$ has half the body iron content of a $3000 \mathrm{~g}_{\text {infant }}{ }^{(44)}$. A study in Indonesia showed that low birth weight interacted with the smaller iron stores associated with women with anaemia during pregnancy and increased an infant's anaemia risk by nearly four times ${ }^{(45)}$.

Mothers with anaemia were about $2 \cdot 0$ times more likely to practise open defecation and, similarly, children with anaemia were 2.7 times more likely to practise open defecation. Among the extreme poor, $46 \%$ practised open defecation at baseline but this reduced to $11 \%$ in two years. Open defecation is associated with increased risk of adverse pregnancy outcomes including preterm births, low birth weight, spontaneous abortions and stillbirths ${ }^{(46)}$. It is worth highlighting the significance of open defecation. Bangladesh has made considerable progress reducing the number of households and people practising open defecation. In $2003,42 \%$ of the population practised open defecation while in 2015 that figure stood at only $1 \%{ }^{(42)}$. Open defecation is an issue that can be eradicated completely in Bangladesh, and this would have a significant impact upon undernutrition.

The World Bank recently reported that Bangladesh had performed better than any other South Asian or Lower Middle-Income country in all criteria except for stunting, and concluded that $52 \%$ of potential productivity was lost due to current education and health conditions ${ }^{(47)}$. In other words, the 'South Asia enigma' still remains. Although Bangladesh has made significant progress in reducing the number of children suffering undernutrition, current rates and prevalence remain high. Recent research has drawn attention to the links between inequality and undernutrition, and to the gap in understanding the experience and impact of undernutrition on the very poorest. This paper attempts to address this gap, however the quantitative study design does not provide information on how household economic empowerment impacts on child and maternal nutrition and more detailed investigation through a qualitative approach should be conducted.
There are three main findings that lead directly to policy reflections. First, even among the country's very poorest, it is possible to achieve very significant improvements in child nutrition through interventions that support household livelihood security. The current study showed significant reductions in undernutrition among extreme poor in Bangladesh and suggests that child undernutrition is a multidimensional phenomenon that requires multipronged and complementary interventions. Specifically, the analysis suggests that future interventions to improve children's nutritional status, especially among the extreme poor, need to focus on the broader goal of household livelihood security. Targeting extreme poor households may be a more preferable option than extending universal coverage. Second, improvements in asset accumulation, health, diets, food security and quality, sanitation, and mothers' nutritional status all have positive impacts upon the nutritional status of children. In particular, this analysis shows strong associations between child undernutrition and the health status of mothers. Positive changes in mothers' health are strongly associated with cash savings, food diversity, and improved sanitation. In policy terms, this suggests continued focus on the mothers of children both in terms of their health status as well as their caring practices. Finally, a significantly higher than average percentage of extremely poor households practise open defecation. There were strong associations between open defecation practices and child stunting, and levels of anaemia as well as energy deficiency in mothers.

\section{Acknowledgements}

Acknowledgements: The authors wish to thank the EEP/ shiree management information systems team, programme managers, survey supervisors, data entry personnel, and the field staff who conducted interviews and collected measurements for the panel surveys. Additionally, we would like to thank the EEP/shiree partner NGOs for helping to administer the annual survey, and to express our special appreciation for the study participants in $\mathrm{EEP} /$ shiree programme. Final thanks are due to the donors, the UK Department for International Development (DFID) and the Swiss Agency for Development and Cooperation (SDC), and the Government of Bangladesh for making the study possible. Financial support: The Economic Empowerment of the Poorest (EEP) programme and its research was funded by the DFID and SCD in partnership with the Government of Bangladesh. Conflict of interest: No conflict of interest. Authorship: R.G. and C.G.N.M.-T. undertook the study design and data analysis. R.G., J.D. and C.G.N.M.-T. drafted the initial paper. J.O. and J.A.J. operated and supervised the surveys, data collection and data entry. All authors have read, contributed and confirmed to the final manuscript. Ethics of buman 
subject participation: The project was approved by the Bangladesh Medical Research Council. Informed consent (written and oral) was obtained from the participants in accordance with the Declaration of Helsinki. Verbal consent was witnessed and formally recorded. Participants could withdraw from the surveys at any point of time. If the participants had severe anaemia they were referred to a doctor/hospital for immediate treatment.

\section{References}

1. Black RE, Allen LH, Bhutta ZA et al. (2008) Maternal and child undernutrition: global and regional exposures and health consequences. Lancet 371, 243-260.

2. UNICEF, World Health Organization, World Bank (2017) Levels and Trends in Child Nutrition: Key Findings of the 2017 Edition. http://www.who.int/nutgrowthdb/jme_ brochoure2017.pdf?ua=1 (accessed 28 November 2018).

3. Grantham-McGregor S, Cheung YB, Cueto S et al. (2007) International child development steering group. Developmental potential in the first 5 years for children in developing countries. Lancet 369, 60-70.

4. Rytter MJH, Kolte L, Briend A et al. (2014) The immune system in children with malnutrition - A systematic review. PLoS One 9, e105017.

5. Darnton-Hill I, Nishida C \& James WP (2004) A life course approach to diet, nutrition and the prevention of chronic diseases. Public Health Nutr 7, 101-121.

6. United Nations System Standing Committee on Nutrition (UNSCN) (2016) Sixth Report on the World Nutrition Situation. Geneva: UNSCN.

7. Shrimpton R, Victora CG, de Onis M et al. (2001) Worldwide timing of growth faltering: implications for nutritional interventions. Pediatric 107, E75.

8. Victora CG, de Onis M, Hallal PC et al. (2010) Worldwide timing of growth faltering: revisiting implications for interventions. Pediatric 125, E473-480.

9. Smith L \& Haddad L (2015) Reducing child undernutrition: past drivers and priorities for the post-MDG era. World Development 68, 180-204.

10. World Economic Forum (2016) Global Competitiveness Report 2016-2017. Geneva: WEF.

11. Ramalingaswami V, Jonsson U \& Rohde J (1996) Nutrition The Asian enigma. In The Progress of Nations pp. 11-17 [P Adamson, editor]. New York: UNICEF.

12. Menon P (2012) Childhood undernutrition in South Asia: perspectives from the field of nutrition. CESifo Economic Studies 58, 274-295.

13. Aguayo VM \& Menon P (2016) Stop stunting: improving child feeding, women's nutrition and household sanitation in South Asia. Matern Child Nutr 12, 3-11.

14. Headey D, Hoddinott J, Ali D et al. (2015) The other Asian enigma: explaining the rapid reduction of undernutrition in Bangladesh. World Development 66, 749-761.

15. Bangladesh Bureau of Statistics (1987) Child Nutrition Survey 1985-86. Dhaka, Bangladesh: Bangladesh Bureau of Statistics.

16. National Institute of Population Research and Training (NIPORT), Mitra and Associates, ICF International (2015) Bangladesh Demographic and Health Survey 2014. Dhaka, Bangladesh, and Rockville, Maryland, USA: NIPORT, Mitra and Associates, and ICF International.

17. Ahmed T, Hossain M, Mahfuz M et al. (2016) Imperatives for reducing child stunting in Bangladesh. Matern Child Nutr 12, 242-245.
18. Nisbett N, Davis P, Yosef S et al. (2017) Bangladesh's story of change in nutrition: strong improvements in basic and underlying determinants with an unfinished agenda for direct community level support, Global Food Security 13, 21-29.

19. Asadullah MN, Savoia A \& Mahmud W (2014) Paths to development: is there a Bangladesh surprise? World Development 62, 138-154.

20. General Economics Division (GED) of Bangladesh Planning Commission (2016) Millennium Development Goals. Bangladesh Progress Report 2015. Dhaka: General Economics Division Planning Commission.

21. Rabbani A, Khan A, Yusuf S et al. (2016) Trends and determinants of inequities in childhood stunting in Bangladesh from 1996/7 to 2014. Int J Equity Health 15, 186.

22. Devine J \& Wood GD (2017) Leaving no-one behind in Bangladesh: the case for a new political settlement. In Extreme Poverty, Growth and Inequality in Bangladesh pp. 31-51. [Devine J, Wood GD, Ali Z, Alam S editors]. Rugby: Practical Action Ltd.

23. The project detail is www.shiree.org (accessed 28 November 2018).

24. Ali Z \& Devine J (2018) Poverty thresholds analysis. In Aiding Resilience among the Extreme Poor in Bangladesh pp. 107131 [Wood GD, Maitrot M, Devine J, editors]. Dhaka: University Press Ltd.

25. Bangladesh Bureau of Statistics (2011) Report of the Household and Income and Expenditure Survey 2010. Dhaka: Bangladesh Bureau of Statistics, Government of Bangladesh.

26. Maxwell D, Watkins B, Wheeler R \& Collins G (2003) The Coping Strategies Index: A tool for rapidly measuring food security and the impact of food aid programmes in emergencies. FAO International Workshop on "Food Security in Complex Emergencies: building policy frameworks to address longer-term programming challenges" Tivoli, 23-25 September 2003, Rome, Italy: FAO.

27. Maxwell D \& Caldwell R (2008) The Coping Strategies Index: Field Methods Manual 2nd Edition, January 2008. Atlanta, GA: Cooperative for Assistance and Relief Everywhere, Inc. (CARE).

28. Food and Agriculture Organization (2010) Guidelines for Measuring Household and Individual Dietary Diversity. Rome, Italy: FAO.

29. Swindale A \& Bilinsky P (2006) Household Dietary Diversity Score (HDDS) for Measurement of Household Food Access: Indicator Guide, Version 2. Food and Nutrition Technical Assistance Project. Washington, DC: Academy for Educational Development.

30. World Health Organization (2006) WHO Child Growth Standards: Length/Height-for-age, Weight-for-Age, Weightfor-Length, Weight-for-Height and Body Mass Index-forAge: Methods and Development. Geneva: WHO.

31. Shetty PS \& James WPT (1994) Body mass index - a measure of chronic energy deficiency in adults. FAO Food Nutr Pap 56, $1-57$.

32. Ulijaszek S \& Kerr DA (1999) Anthropometric measurement error and the assessment of nutritional status, Bri J Nutr $\mathbf{8 2}$, $165-177$.

33. World Health Organization, UNICEF, UNU (2001) Iron Deficiency Anaemia: Assessment, Prevention and Control, A Guide for Programme Managers. Geneva: WHO.

34. Hasan MT, Soares Magalhaes RJ, Williams GM et al. (2015) Forecasting the progress towards the target of Millennium Development Goal 1C in children under 5 years of age in Bangladesh. Public Health Nutr 18, 1728-1736.

35. Bhutta ZA, Ahmed T, Black RE et al. (2008) What works? Interventions for maternal and child undernutrition and 
survival. Lancet. 371, 417-44. doi: 10.1016/S0140-6736(07) 61693-6.

36. Bhutta ZA, Das JK, Rizvi A et al. (2013) Evidence-based interventions for improvement of maternal and child nutrition: what can be done and at what cost? Lancet 382, 452-477. doi: 10.1016/S0140-6736(13)60996-4.

37. Ruel MT, Alderman H \& Maternal and Child Nutrition Study Group (2013) Nutrition-sensitive interventions and programmes: how can they help to accelerate progress in improving maternal and child nutrition? Lancet 3825, 36-51. doi: 10.1016/S0140-6736(13)60843-0.

38. Holmes R, Farrington J, Rahman T et al. (2008) Extreme poverty in Bangladesh: Protecting and Promoting Rural Livelihoods, Overseas Development Institute. https://www. odi.org/sites/odi.org.uk/files/odi-assets/publications-opinionfiles/2342.pdf (accessed on 28 November 2018).

39. Ngwira A, Munthali ECS \& Vwalika KD (2017) Analysis on the association among stunting, wasting and underweight in Malawi: an application of a Log-Linear model for the threeway table. J Public Health Afr 8, 620. doi: 10.4081/jphia. 2017.620 .

40. Martorell R \& Young MF (2012) Patterns of stunting and wasting: potential explanatory factors. Adv Nutr 3, 227-233. doi: 10.3945/an.111.001107.
41. de Groot R, Palermo T, Handa S et al. (2016) Cash transfer and child nutrition: passways and impacts. Dev Policy Rev, 35:621-643. doi: 10.1111/dpr.122555.

42. Richards K (2015) Malnutrition in Bangladesh: Harnessing Social Protection for the Most Vulnerable. London: The Save the Children Fund.

43. Scholl TO (2011) Maternal iron status: relation to fetal growth, length of gestation and the neonate's iron endowment, Nutr Rev 69, S23-S29.

44. Faldella G, Corvaglia L \& Lanari M et al. (2003) Iron balance and iron nutrition in infancy. Acta Paediatr Suppl 441, $82-85$.

45. de Pee S, Bloem MW, Sari M et al. (2002) The high prevalence of low hemoglobin concentration among Indonesian infants aged 3-5 months is related to maternal anemia. J Nut 132, 2215-2221.

46. Padhi BK, Baker KK, Dutta A et al. (2015) Risk of adverse pregnancy outcomes among women practicing poor sanitation in rural India: a population-based prospective cohort study, PLoS Med 12, e1001851.

47. World Bank (2018) Press Release October 11, 2018. https:// www.worldbank.org/en/news/press-release/2018/10/11/ New-World-Bank-Human-Capital-Index-Bangladesh-HasDone-Well-Can-Do-Better (accessed November 2018). 